\title{
One-Carbon Metabolism and Nonalcoholic Fatty Liver Disease: The Crosstalk between Nutrients, Microbiota, and Genetics
}

\author{
Anna Radziejewska ${ }^{a}$ Agata Muzsik ${ }^{a}$ Fermín I. Milagrob-d \\ J. Alfredo Martínez ${ }^{\text {b-d }}$ Agata Chmurzynska ${ }^{a}$ \\ ${ }^{a}$ Institute of Human Nutrition and Dietetics, Poznań University of Life Sciences, Poznań, Poland; bepartment of \\ Nutrition, Food Science and Physiology, Centre for Nutrition Research, University of Navarra, Pamplona, Spain; \\ 'Navarra's Health Research Institute (IdiSNA), Pamplona, Spain; ${ }^{\text {d} C e n t r o ~ d e ~ I n v e s t i g a c i o ́ n ~ B i o m e ́ d i c a ~ e n ~ R e d ~ d e ~ l a ~}$ \\ Fisiopatología de la Obesidad y Nutrición (CIBERobn), Instituto de Salud Carlos III, Madrid, Spain
}

\section{Keywords}

Nonalcoholic fatty liver disease - One-carbon metabolism . Fetal programming

\section{Abstract}

The prevalence of nonalcoholic fatty liver disease (NAFLD) is increasing worldwide. Its etiology includes nutritional, genetic, and lifestyle factors. Several mechanisms may link onecarbon metabolism - the associated metabolic pathways of folate, methionine, and choline - to the onset of NAFLD. In this review, we attempted to assess how choline, folate, methionine, and betaine affect NAFLD development, mainly through their role in the secretion of very low-density lipoproteins (VLDL) from the liver. We also reviewed recent articles that have described the relation between microbiota metabolism and NAFLD progression. Moreover, we describe the effect of single-nucleotide polymorphisms (SNP) in genes related to one-carbon metabolism and disease prevalence. We additionally seek SNP identified by genome-wide associations that may increase the risk of this disease. Even though the evidence available is not entirely consistent, it seems that the concentrations of choline, methionine, fo- late, and betaine may affect the progression of NAFLD. Since there is no effective therapy for NAFLD, further investigations into the link between nutrition, gut microbiota, genetic factors, and NAFLD are still necessary, with a particular emphasis on methyl donors.

(c) 2019 The Author(s)

Published by S. Karger AG, Basel

\section{Nonalcoholic Fatty Liver Disease}

Nonalcoholic fatty liver disease (NAFLD) is a process of pathological fat deposition in the liver that has a number of subtypes, such as hepatic steatosis, nonalcoholic hepatitis (NASH), and liver fibrosis [1]. The liver ultrasound image of NAFLD resembles the changes that occur in alcoholic fatty liver. The pathophysiological mechanisms in NAFLD are complex and not fully understood. However, it is a multifactorial disease that is influenced by nutritional and genetic factors [2-4].

Epidemiological studies indicate that the prevalence of NAFLD is approximately $10-35 \%$ of the general global population $[5,6]$. The risk of developing NAFLD is related to the onset of obesity and metabolic syn-

\begin{tabular}{ll}
\hline KARGER & $\begin{array}{l}\text { @ } 2019 \text { The Author(s) } \\
\text { Published by S. Karger AG, Basel }\end{array}$ \\
E-Mail karger@karger.com & $\begin{array}{l}\text { This article is licensed under the Creative Commons Attribution- } \\
\text { NonCommercial-NoDerivatives 4.0 International License (CC BY- } \\
\text { NC-ND) (http://www.karger.com/Services/OpenAccessLicense). } \\
\text { Nww.karger.com/lfg and distribution for commercial purposes as well as any dis- } \\
\text { tribution of modified material requires written permission. }\end{array}$
\end{tabular}

Agata Chmurzynska

Institute of Human Nutrition and Dietetics, Poznań University of Life Sciences Wojska Polskiego 31

PL-60-624 Poznań (Poland)

E-Mail agata.chmurzynska@up.poznan.pl 
drome (MetS). A relationship has been observed between NAFLD and abnormal glucose tolerance, insulin resistance, dyslipidemia, and type 2 diabetes. In addition, it has been observed that fatty liver can occur both in people with a normal body mass index (BMI) $(10-24 \%$ of the population has fatty liver) and in $95 \%$ of adults with obesity $[2,7]$. Research has also indicated the important role of nutrition and physical activity in the development of NAFLD $[2,3,7]$. The risk factors for the development of NAFLD fibrosis and cirrhosis are thus: age, type 2 diabetes, hypertension (>140/90 $\mathrm{mm} \mathrm{Hg}$ or treated), a high BMI (women >32.3), elevated alanine aminotransferase (ALT) (>twice the upper norm), a high ratio of aspartate to alanine aminotransferase (AST/ALT $>1$ ), and high triacylglycerol levels (TG $>1.7 \mathrm{mmol} / \mathrm{L}$ ) [3, 4, 8-10]. Moreover, there is evidence or a relationship between NAFLD and systemic inflammation, suggesting that inflammation could be the link between NAFLD and insulin resistance [11].

Several nutritional and lifestyle factors, including overweight in childhood and adolescence, high intakes of fat, fructose, and sodium, and low physical activity levels, have been associated with the development of NAFLD [1]. In this context, high fat and carbohydrate intakes have been associated with NAFLD development. The excessive intake of these macronutrients in patients with fatty liver is positively correlated with glucose disturbances and a low insulin sensitivity, which have been found to be linked to NAFLD. A high carbohydrate consumption plays a key role in liver de novo lipogenesis. A high dietary sugar level and the intake of sugar-sweetened beverages (common in the Western diet) are associated with increased visceral fat and TG and a high risk of MetS. In addition, fructose intake is one of the independent factors related to NAFLD development $[12,13]$. As lipogenic compounds, fructose and sucrose are involved in increased oxidative stress, as well as in increased TG synthesis and accumulation in the liver. Unbalanced proportions of polyunsaturated (PUFA), saturated (SFA), and trans fatty acids (transFA) have been found to be involved with the progression of NAFLD. A lower ratio of n- 6 to n-3 PUFA and a lower intake of SFA and transFA are recommended in NAFLD therapy, and they are associated with decreased total cholesterol and TG levels and lower inflammation $[14,15]$.

High physical activity is positively correlated with good health and prevents obesity and MetS. It has been indicated that physical activity is an independent factor for weight reduction in NAFLD treatment. Increasing physical activity in patients with NAFLD is associated with decreased levels of liver enzymes, TG, and LDL-C, and with improved insulin sensitivity [16].

Nutritional recommendations point primarily to the need to reduce body weight in order to reduce the risk of NAFLD. The effectiveness of supplementation with fatty acids has also been considered. For example, it has been observed that higher intakes of eicosapentaenoic acid and docosahexaenoic acid can reduce the risk of fatty liver disease [7, 17-23]. The present review focuses on the role of methyl donors on the etiology, prevention, and therapy of NAFLD and associated comorbidities. In this context, NAFLD has been associated not only with changes in lipid metabolism but also with disorders in one-carbon metabolism [24-29]. Thus, supplementation with different methyl donors such as choline and betaine has been proposed as a therapeutic tool to prevent or treat NAFLD, although a high methyl donor intake may also have detrimental effects.

\section{One-Carbon Metabolism}

One-carbon metabolism involves interrelated methionine and folate pathways. Methionine is an essential amino acid whose status in the organism depends on its intake from diet, protein breakdown, and its synthesis through remethylation of homocysteine (Hcy). Hcy can be methylated back to methionine by a number of reactions as follows:

- remethylation by methionine synthase, which is limited by the availability of 5-methyltetrahydrofolate (methyl-THF) or betaine derived from choline;

- transsulfuration, which converts Hcy to cysteine; however, this pathway is limited to the liver, kidneys, intestine, and pancreas.

Methionine may then be transformed to S-adenosylmethionine (SAM), which is used as a universal methyl donor in the majority of methyltransferase reactions, such as phospholipid synthesis and methylation of nucleic acid and protein [30]. SAM is then converted to SAH (S-adenosyl-L-homocysteine) and subsequently to Hcy.

The folate cycle is linked to the methionine cycle by this Hcy remethylation reaction. Folate absorbed from food is converted to methyl-THF, the main form of folate in human plasma. Otherwise, folic acid supplementation enters the cycle via dihydrofolate (DHF). The principal role of folate in these pathways is to donate or accept one-carbon units. The central acceptor molecule is THF. THF is converted to 5,10-methylene tetrahydro-
Radziejewska/Muzsik/Milagro/Martínez/ Chmurzynska 


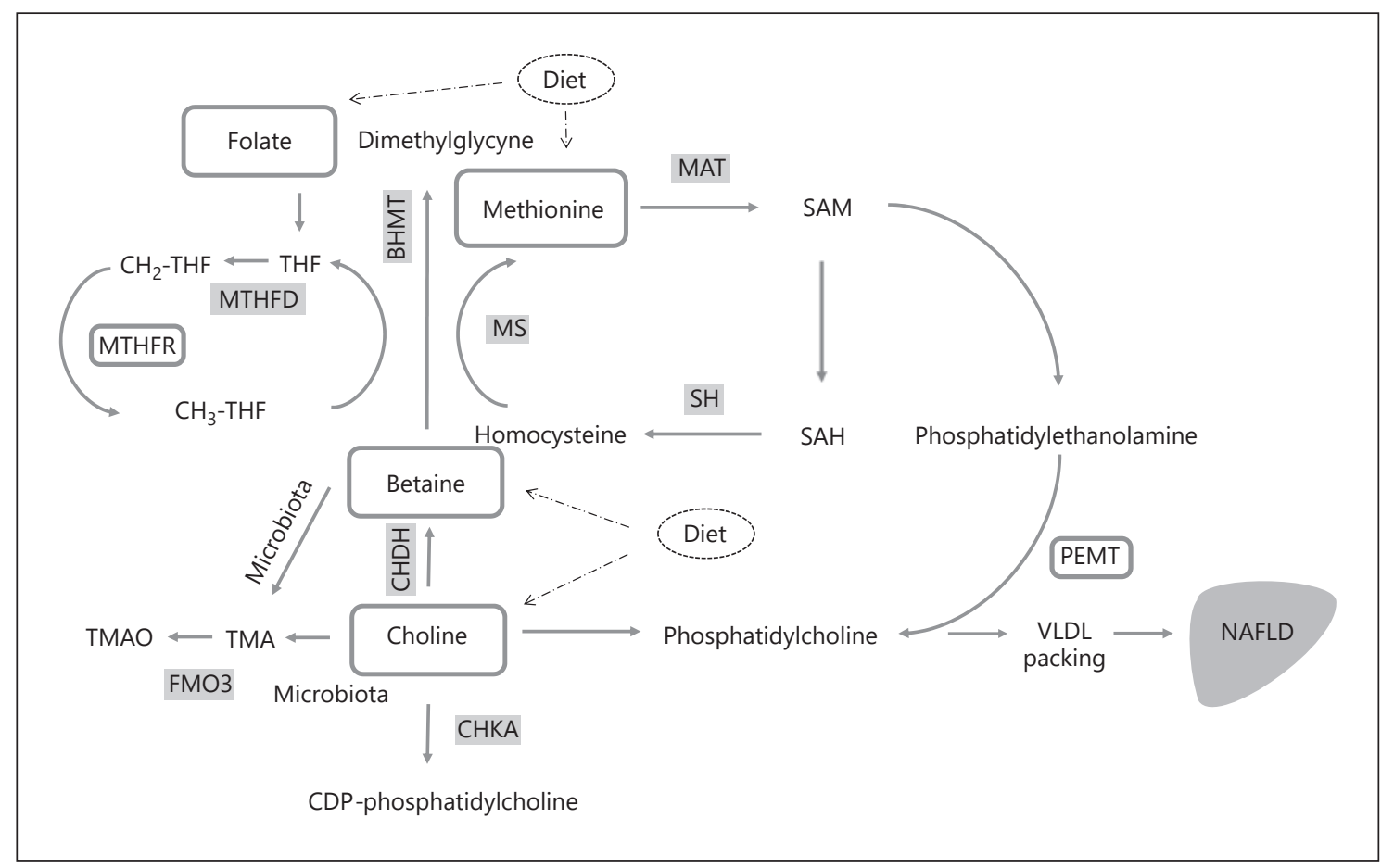

Fig. 1. Scheme of selected reactions of one-carbon metabolism. BHMT, betaine Hcy S-methyltransferase; $\mathrm{CHDH}$, choline dehydrogenase; MAT, methionine adenosyl transferase; MS, methionine synthase; SAH, S-adenosylhomocysteine; SH, SAH hydrolase; MTHFD, methylenetetrahydrofolate dehydrogenase; FMO3, flavin-containing monooxygenase 3.

folate (methylene-THF) and then reduced by the enzyme methylene-THF reductase (MTHFR), leading to the formation of methyl-THF. The methyl group of methyl-THF can only be used in the Hcy remethylation reaction [31] (Fig. 1).

Choline can be synthesized endogenously from phosphatidylethanolamine (PE), which is converted to phosphatidylcholine (PC) by the enzyme PE methyltransferase (PEMT). The expression of the PEMT gene is known to be regulated by estrogens [32]. Trimethylamine (TMA) is a gut microbiota-derived metabolite synthesized from choline and betaine (Fig. 1). The concentration of TMA substrates is dependent on diet. TMA is oxidized in the liver to form TMA-N-oxide (TMAO), which correlates with cardiovascular disease risk [33].

Several mechanisms may link one-carbon metabolism and NAFLD, but it seems that the most relevant one is synthesis of VLDL and the export of lipids from the liver. Choline participates in the packaging and exporting of TG in VLDL and aberrant levels of one-carbon metabolites may lead to a reduced VLDL secretion and then fat accumulation in the liver [34].

One-Carbon Metabolism and NAFLD

\section{Methionine}

Methionine is an essential amino acid that plays a key role as a regulator of a number of cellular functions [35$37]$. It is metabolized mainly in the liver [37, 38]. Methionine is one of the major dietary sources of methyl donor groups [39]. It has been extensively reported that methionine deficiency induces steatosis or fatty liver disease in a few days in animal models [40-43].

Intrahepatic lipid accumulation could be caused by impaired VLDL secretion. Furthermore, methionine is a precursor of PC and choline, which can induce disturbances in lipid metabolism and lipid accumulation in the liver $[44,45]$. Moreover, a methionine-choline-deficient diet in mice has been found to decrease the activity of SCD-1, an enzyme involved in TAG metabolism. Abnormal TAG secretion is also the reason for the accumulation of intrahepatic lipid [46].

Several studies conducted in mice fed methionine-deficient or methionine-supplemented diets showed that these diets led to alterations in the expression of genes involved in lipid metabolism. Moreover, these studies 
Table 1. SNP associated with NAFLD risk identified in genome-wide association and candidate gene studies and SNP associated with the odds of developing choline deficiency

\begin{tabular}{|c|c|c|c|c|c|c|}
\hline Gene & Gene name & rs & RAF & OR & $p$ value & Study \\
\hline \multicolumn{7}{|c|}{ SNP associated with NAFLD risk identified in genome-wide association studies } \\
\hline LCP1 & Lymphocyte cytosolic protein 1 & rs7324845-A & 0.096 & 3.29 & $3 \times 10^{-6}$ & Adams et al. [97] \\
\hline GC, SLC4A4 & $\begin{array}{l}\text { GC vitamin D-binding protein, solute } \\
\text { carrier family } 4 \text { member } 4\end{array}$ & rs222054-C & 0.301 & 2.54 & $1 \times 10^{-6}$ & Adams et al. [97] \\
\hline AL365220.1, PLPPR4 & $\begin{array}{l}\text { ENSG00000233983 (pseudogene) } \\
\text { phospholipid phosphatase-related } 4\end{array}$ & rs $12743824-\mathrm{C}$ & 0.441 & 2.3 & $5 \times 10^{-6}$ & Adams et al. [97] \\
\hline PNPLA3 & $\begin{array}{l}\text { Patatin-likep phospholipase domain } \\
\text { containing } 3\end{array}$ & rs738409-G & 0.484 & 1.66 & $1 \times 10^{-10}$ & Kawaguchi et al. [120] \\
\hline SAMM50, PNPLA3 & $\begin{array}{l}\text { Sorting and assembly machinery } \\
\text { component, patatin like phospholipase } \\
\text { domain containing } 3\end{array}$ & rs738491-T & 0.52 & 1.6 & $1 \times 10^{-18}$ & Kawaguchi et al. [120] \\
\hline PNPLA3 & $\begin{array}{l}\text { Patatin-like phospholipase domain } \\
\text { containing } 3\end{array}$ & rs738409-G & 0.398 & 1.54 & $2 \times 10^{-15}$ & Chung et al. [121] \\
\hline SAMM50 & Sorting and assembly machinery component & rs2143571-A & 0.395 & 1.44 & $2 \times 10^{-11}$ & Chung et al. [121] \\
\hline GCKR & Glucokinase regulator & rs1260326-T & 0.57 & 1.38 & $1 \times 10^{-9}$ & Kawaguchi et al. [120] \\
\hline GATAD2A & GATA zinc finger domain containing $2 \mathrm{~A}$ & rs4808199-A & 0.27 & 1.37 & $2 \times 10^{-8}$ & Kawaguchi et al. [120] \\
\hline GCKR & Glucokinase regulator & rs780094-T & 0.57 & 1.35 & $2 \times 10^{-8}$ & Kawaguchi et al. [120] \\
\hline ZNF512, AC074091.1 & $\begin{array}{l}\text { Zinc finger protein } 512 \\
\text { ENSG00000259080 gene }\end{array}$ & rs1881396- $\mathrm{T}$ & 0.71 & 1.34 & $1 \times 10^{-6}$ & Kawaguchi et al. [120] \\
\hline MUM1 & Melanoma associated antigen & rs2668423-T & 0.33 & 1.3 & $1 \times 10^{-6}$ & Kawaguchi et al. [120] \\
\hline \multicolumn{7}{|c|}{ SNP associated with NAFLD in candidate gene studies } \\
\hline PEMT & $\begin{array}{l}\text { Phosphatidylethanolamine } \\
\text { N-methyltransferase }\end{array}$ & rs7946-A & 0.46 & & & Song et al. [76] \\
\hline MTHFR & Methylenetetrahydrofolate reductase & $\begin{array}{l}\text { rs1801131-C } \\
\text { rs1801133-T (NASH) }\end{array}$ & $\begin{array}{l}0.29 \\
0.30\end{array}$ & & & $\begin{array}{l}\text { Catalano et al. [122] } \\
\text { Sazci et al. [123] }\end{array}$ \\
\hline
\end{tabular}

RAF, risk allele frequency.

showed an increase in SAH and Hcy levels compared to controls. However, methionine-supplemented rats had almost twice as high SAH and Hcy concentrations compared to the methionine-deficient group. Administration of the methionine-deficient diet resulted in the development of hepatic steatosis, which was not observed in the methionine-supplemented diet. Hepatic triglyceride concentrations were higher in both experimental groups compared to the control group. These pathophysiological molecular events may ultimately lead to lipid accumulation in the liver, triggering the development of NAFLD
[47-49]. Hepatic methionine was depleted in mice that developed marked steatosis and extensive fibrosis while on a high-fat high-cholesterol diet, while the SAM/methionine ratio, SAH, and Hcy significantly increased [37]. Methionine depletion leads to liver steatosis in mice. However, to achieve the NAFLD model, a methionineand choline-deficient diet is usually used. Rodents fed a methionine- and choline-deficient diet develop the whole spectrum of liver pathologies from macrovesicular steatosis to hepatic fibrosis [50]. 


\section{Folate}

It has been reported that folate depletion may cause oxidative stress in the liver and lead to the development of NAFLD [51]. Folate depletion also leads to the utilization of betaine and choline for Hcy remethylation, disrupting choline metabolism. This mechanism may contribute to increased steatosis, at least in mice $[24,52]$. Moreover, depletion of dietary folates results in increased expression of genes related to lipogenesis that promote lipid accumulation [53]. The mechanisms of lipid export from the liver through VLDL secretion were also disturbed in mice fed folate-deficient diets [24, 52]. One mechanism that is likely involved in this process is folate participation in SAM synthesis, which is subsequently involved in PC synthesis and VLDL secretion (Fig. 1). This mechanism still appears to be unclear, since PC synthesis can occur independently of one-carbon metabolism, i.e., via the de novo pathway (the Kennedy pathway) [54]. It has also been reported that, when rats with NAFLD are treated with folic acid, an improvement in the SAM/SAH ratio and one-carbon metabolism is noticed [55]. Moreover, an in vitro study showed that administration of folic acid to the medium of primary chicken hepatocytes with NAFLD reduced triglyceride deposition by suppressing fatty acid synthesis [56].

Pregnant rats fed a folic acid-depleted diet or a control diet had similar TG concentrations in the liver. In contrast, rats fed a diet deficient in folic acid, methionine, and choline showed higher TG levels in the liver compared to the control group [57].

Interestingly, excessive folic acid levels in the diet may result in effects similar to folic acid deficiency. Mthfrt/mice fed a $10 \times$ higher folic acid dose than the control group showed a reduced concentration of the MTHFR protein, which resulted in hepatocyte degeneration. This condition has been referred to as a pseudo-MTHFR deficiency [58].

An observational study in humans did not find differences in folate and $\mathrm{B}_{12}$ vitamin levels when comparing 30 patients with biopsy-proven NAFLD with 24 healthy controls [59]. A similar result was observed in larger groups (NAFLD, $n=134$; control, $n=134$ ) [60]. On the contrary, another study showed that a low serum folic acid concentration was an independent risk factor of NAFLD in a Chinese population [61]. Moreover, low folate and vitamin $\mathrm{B}_{12}$ levels were correlated with $\mathrm{NASH}$ severity [62]. In obese patients, despite an adequate intake of folate, serum folate levels were lower than in healthy individuals [63]. Interestingly, a high-fat diet led to a de-

One-Carbon Metabolism and NAFLD crease in hepatic folate levels and suppressed the expression of hepatic folate transporters in mice [64]. The relation between folate and obesity has not been well understood. It is not known whether a folate deficiency leads to obesity or obesity causes a folate deficiency.

In summary, the relation between folate concentrations and NAFLD has been observed and one of the underlying mechanisms is participation of folate in SAM synthesis, but other pathways may also be involved.

\section{Choline and Betaine}

Different animal models have been used to induce NAFLD-like disorders. However, comparison and interpretation of the results can be confusing, because different models show different levels of steatosis, insulin resistance, and steatohepatitis. Methionine-deficient and choline-deficient rats developed a higher degree of steatosis, a decreased antioxidant response, and progression to steatohepatitis compared to choline-depleted rats. Moreover, hepatocellular damage, as assessed by increased plasma ALT, was observed in methionine-deficient and choline-deficient rats [65].

Pemt-/- mice fed a choline-deficient diet developed a severe lipid pathology after 3-4 days of consuming the choline-depleted diet [66], presenting a significant decrease in hepatic and plasma PC levels and an increase in hepatic TG levels. Pemt-/- mice fed a choline-supplemented diet did not display liver damage and had normal hepatic and plasma PC levels, as well as normal hepatic TG levels [67].

Humans fed a choline-deficient diet for 3-weeks deplete their stores of choline and start to develop liver dysfunction [68]. In a human study encompassing 664 subjects, a decreased choline intake was associated with increased fibrosis in postmenopausal women with NAFLD but not in children, men, or premenopausal women, in whom no such association was found [69]. Another study showed an association between a lower choline intake and the risk of NAFLD in middle-aged and older Chinese women with a normal body weight. The same study also observed a stronger association of choline intake with fatty liver in men with lower saturated fat intakes; the authors speculated that a higher consumption of fat may induce gut bacterial dysbiosis. That could lead to an alteration in microbiota choline metabolism and a reduced choline bioavailability to the host [70].

Adult rats eating a choline-deficient diet have been shown to develop liver dysfunction and fatty liver [68]. In 
humans, gender and menopausal status also affect the response to a choline-deficient diet. Men and postmenopausal women more frequently developed organ dysfunction, but this did not hold true for most premenopausal women [71]. This could be related to the estrogen status of younger women. In this respect, the PEMT enzyme synthesizes de novo PC in the liver. This enzyme is encoded by the PEMT gene, which is induced by estrogens, due to the presence of several estrogen response elements in its promoter region. The estrogen concentration is higher in premenopausal women than in postmenopausal women, and this mechanism may protect young women from choline depletion. In another experiment, postmenopausal women receiving placebo were 4 times more likely to develop liver dysfunction than estrogen-treated postmenopausal women [72].

When it comes to choline supplementation, it has been reported that it improves or reverts liver steatosis, but no interventional studies have been undertaken to analyze whether choline supplementation is able to prevent NAFLD or reduce NAFLD progression $[73,74]$.

Betaine supplementation has a possibly beneficial effect on fatty liver disease on account of the contribution of betaine to PC and VLDL synthesis (Fig. 1). Betaine treatment has also been shown to decrease the Hcy concentration, as compared to high-fat diet and high-sucrose diets, which may also have an impact on disease development $[75,76]$. Oral betaine treatment has been proposed as a treatment for alcoholic liver disease [77, 78], as it has been observed that betaine decreases the total triglyceride and cholesterol concentrations in the livers of rats with alcoholic fatty liver [79]. In mice with fat-induced NAFL, betaine also reduced triglycerides, hepatic fat, and hepatic steatosis while improving insulin resistance [75]. Another study showed that betaine may ameliorate fatty liver in mice with high-sucrose-diet-induced hepatic steatosis [76].

A different approach was applied to supplementation with a mixture of methyl donors (betaine, choline, vita$\min B_{12}$, and folic acid). Folate, as one of the methyl donors, plays a key role in the production of SAM. However, in folate deficiency, betaine and choline supplementation of these nutrients may be a beneficial alternative form of methyl donor. In addition, deficiencies in compounds associated with the one-carbon metabolism such as folate, methionine, choline, or vitamin $\mathrm{B}_{12}$ can affect abnormal SAM levels and then affect histone modifications [80]. Rats receiving this methyl donor cocktail were protected from liver fat accumulation induced by a high-fat and high-sucrose diet $[81,82]$. Interestingly, another study showed that methyl donor supplements may prevent lipid accumulation in the liver but are unable to reverse this condition in mice [83]. However, a bioinformatic analysis has shown that NAFLD induced by one-carbon donor deficiency in rodents only poorly represents human NAFLD on the transcriptional level [27].

In addition to changes associated with choline or betaine deficiencies, it is also worth noting the potential benefits of supplementing these nutrients. In a study in male mice with a metabolic phenotype of Pemt-/-I Ldlr-/- that were fed a high-fat diet with a choline content of $1.3 \mathrm{~g} / \mathrm{kg}$, it was shown that choline supplementation had no preventative effect against fatty liver. However, they were able to maintain normal blood cholesterol levels and it improved functioning and prevention of adverse liver changes [84].

\section{Gut Microbiota}

The intestinal microbiota may promote the onset and progression of NAFLD $[85,86]$. Two main mechanisms have been proposed to explain the association between gut microbiota and NAFLD, i.e., alcohol-producing bacteria and one-carbon microbiota metabolism. Gut microbial genera such as Escherichia, Bacteroides, Bifidobacterium, and Clostridium [87] and also Klebsiella pneumonia [88] are able to produce alcohol that may promote liver inflammation. It has been reported that children with NAFLD have a distinct microbiome compared to that of healthy counterparts, with more alcohol production [89]. It is well known that alcohol induces steatosis and oxidative stress in the liver, which may promote fatty liver, hepatitis, and cirrhosis [90]. Moreover, microbiota may modulate one-carbon metabolism. For example, Bifidobacterium and Lactobacillus are able to produce folate that may alter host folate levels [91]. An alternative mechanism is alteration of one-carbon metabolism by microbiota, which impairs VLDL secretion. Intestinal bacteria may reduce the choline pool of the host, mimicking the effects of choline-deficient diets and causing hepatic fat accumulation [92].

On the other hand, choline is a dietary precursor of TMA that is subsequently oxidized to TMAO in hepatocytes. An adverse association has been found between circulating TMAO concentrations and the presence and severity of NAFLD [93]. A recent meta-analysis showed a positive dose-dependent association between TMAO plasma levels and increased cardiovascular risk and allcause mortality. However, no causal evidence has been 
provided, also in NAFLD [94]. It has been also reported that TMAO may alter lipid metabolism and glucose tolerance [95]. However, it is not known whether free choline itself or other metabolites like TMAO contribute to such an effect [96].

\section{Gene Polymorphisms}

NAFLD progression depends on the complex interplay between environmental and genetic factors. The idea that NAFLD is related to the genetic background is based on the fact that NAFLD development differs between populations, even though it does not always correlate with differences in the prevalence of environmental risk factors. Genome-wide association studies have identified single-nucleotide polymorphisms (SNP) that increase the risk of NAFLD occurrence. These are mostly associated with fatty acid metabolism, insulin resistance, oxidative stress, and fibrosis development. The most important SNP associated with NAFLD development are presented in Table 1; the OR there range from 1.3 to 3.29. The polymorphism rs7324845, located in the LCP1 gene, has the strongest effect on NAFLD presence. The $L C P 1$ gene is located on chromosome 13 and encodes a cytosolic actinbinding protein called plastin 1 . This polymorphism has been associated with chemotherapy-induced hypertriglyceridemia, which suggests that this gene plays a role in lipid metabolism [97].

To date, several SNP in genes related to one-carbon metabolism have been associated with NAFLD $[98,99]$. PEMT is an enzyme that catalyzes the reaction of de novo PC synthesis in the liver. Song et al. [25] showed for the first time that the rs7946 SNP in PEMT (a G-to-A substitution in exon 8 resulting in the replacement of valine by methionine) impairs the activity of the enzyme. AA homozygotes were more frequent in the NAFLD subpopulation than in the controls [25]. Another study of a Japanese population reported that rs7946 increased the susceptibility to NASH. Although this SNP is very rare in the Japanese population, it was demonstrated that the A allele was more frequent in NASH patients than in controls. Moreover, heterozygote patients had lower BMI values than patients with wild-type homozygotes, which may suggest that this SNP is a risk factor for NASH [100].

Another polymorphism with a very strong association with choline depletion and fatty liver is G1958A (rs2236225), which is located in MTHFR1, a gene involved in folate metabolism. It has been reported that premenopausal women carrying this risk variant are 15 times more likely to develop organ dysfunction on a low-choline diet [101].

Other polymorphisms that have been associated with NAFLD susceptibility are the C677T (rs1801133) and A1298C (rs1801131) variants of the MTHFR gene. However, the association between these SNP and susceptibility to NAFLD is controversial. Several studies have investigated this relation $[60,102,103]$, and one meta-analysis concluded that the T/T genotype of the C677T polymorphism and the C/C genotype of MTHFR A1298C under the recessive model were associated with a higher susceptibility to NAFLD (OR $=1.42, p=0.006$; OR $=2.08, p<$ 0.0001) [103].

Corbin et al. [104] identified 260 SNP across 21 genes of one-carbon metabolism, with PNPLA3 rs738409 being strongly associated $(p=0.02)$ with hepatic steatosis. Since individual SNP have only small effects on liver steatosis, the authors used an unsupervised hierarchical clustering approach that revealed patterns of SNP across relevant genes that were highly associated with steatosis status $(p=0.0002)$ [104]. In another study analyzing the relationship between SNP in genes of one-carbon metabolism and the risk of choline deficiency, rs2236225 (MTHFD1), rs12676(CHDH), rs12325817, and rs4646343 (PEMT) were associated with increased odds of organ dysfunction.

SNP of the genes involved in one-carbon metabolism may alter the risk of fatty liver. Moreover, gene-nutrient interactions may further contribute to this but alter this risk. More studies, however, are necessary to fully understand this interplay.

\section{Fetal Programming}

The intrauterine and early-life environment may affect long-term health; this phenomenon is called fetal programming [105]. There are several factors that create the intrauterine environment. These include maternal metabolic health, nutritional status, and current nutrient intake [106]. It has been hypothesized that the fetus adapts to the unbeneficial environment during pregnancy, but this adaptation may have adverse health effects when postnatal conditions are more favorable [107].

For example, high maternal sugar levels lead to hyperglycemia of the fetus and trigger insulin synthesis and affect fetal growth and obesity [108]. Also, mothers who have a high-fat diet may promote lipid accumulation in the infant liver, possibly leading to NAFLD development $[109,110]$. One-carbon metabolism may affect lipid ac- 
cumulation in the liver, and the authors thus investigated how one-carbon nutrient intake during pregnancy affects the livers of the mother and fetus. Fetuses of dams fed a diet deficient in methionine, folic acid, and choline had more extensive changes in fat metabolism than fetuses of mothers fed a folic acid-deficient diet. This may suggest that the other methyl group donor carriers are involved in or may protect lipid metabolism during folic acid deficiency, or that stores of this nutrients were employed [111].

A deficiency of methyl donors, folate, and vitamin $B_{12}$ during pregnancy and lactation in rats results in a low birth weight and microvascular steatosis in pups [112]. The link between methyl donor deficiency and epigenomic deregulation of energy metabolism has also been studied in a rat model, where it was shown that liver steatosis resulted from hypomethylation of PGC1- $\alpha$, which impairs fatty acid oxidation. Rat pups from dams subjected to methyl donor deficiency during gestation and lactation had microvascular steatosis, with increased triglycerides, decreased methionine synthase, and a lower SAM/S-adenosylhomocysteine ratio compared to the dams [113].

Not only B vitamin or choline deficiency during pregnancy may have a programming effect. Protein malnutrition by increased oxidative stress may lead to fatty liver [107]. Other factors, including fetal undernutrition, may also contribute to the development of fatty liver. A population-based study showed that subjects exposed to the Chinese famine in early life had moderate to severe NAFLD as adults [114]. The Helsinki birth cohort study showed that men born during the war had a higher risk of developing NAFLD during adulthood [115]. On the other hand, fetal overnutrition caused by maternal obesity or gestational diabetes mellitus also may lead to fat accumulation in the infant liver [116]. A recent study showed that both a high birth weight and a low birth weight are more present often in children with NAFLD than in the general population. However, a high birth weight was a predictor of more severe steatosis [117].

There are several molecular and cellular mechanism that are responsible for the fetal programming phenomenon. One of them is constituted by persistent epigenetic alterations such as DNA methylation or histone acetylation changes stimulated by the prenatal factors. Epigenetics plays a key role in programming of cells during embryonic development and may act as a cellular memory. Since nutrients such as folate, betaine, and choline are methyl donors, it has been hypothesized that their intake and availability may affect this mechanism [118].
Deficiencies of methyl donors, folate, and vitamin $B_{12}$ during pregnancy and lactation in rats resulted in a low birth weight and microvascular steatosis in pups [112].

Even though there is evidence that one-carbon metabolism leads to fatty liver, there is still a knowledge gap concerning this effect in a transgenerational model. One recent study showed that prenatal dietary restriction did not induce broad changes in hepatic DNA methylation of the genes involved in lipid or carbohydrate metabolism in 3 generations of female rats [119].

\section{Conclusions}

In this review, we attempted to assess how methyl donors affect NAFLD, also in the context of gut microbiota and SNP. Considering different models, the evidence is not entirely consistent but it seems that the status of choline, methionine, folate, and betaine may affect the progression of NAFLD. Since treatment with these particular nutrients results in different onsets on NAFLD, further investigation is still necessary, especially in humans. Association studies indicate that several SNP in one-carbon metabolism-related genes may affect metabolic handling of methyl-donors and presumably fat liver accumulation. Even though the relationship between microbiota and NAFLD is still not clear, it seems that the gut microbiota composition may alter the host metabolism and influence the risk of this disease. Since there is no effective therapy for NAFLD, further investigations into the link between nutrition, gut microbiota, genetic factors, and NAFLD are still needed, with a particular emphasis on methyl donors.

\section{Disclosure Statement}

The authors declare that they have no conflict of interests.

\section{Funding Sources}

This research received no specific grants from any funding agency in the public, commercial, or not-for-profit sector.

\section{Author Contributions}

A.R., A.M., and A.C. wrote this paper. F.I.M. conceived this review and critically revised the content of this article. A.M. advised on this review and made an intellectual contribution to it.
Radziejewska/Muzsik/Milagro/Martínez/ Chmurzynska 


\section{References}

1 Younossi Z, Anstee QM, Marietti M, Hardy T, Henry L, Eslam M, et al. Global burden of NAFLD and NASH: trends, predictions, risk factors and prevention. Nat Rev Gastroenterol Hepatol. 2018 Jan;15(1):11-20.

2 Hassan K, Bhalla V, El Regal ME: Nonalcoholic fatty liver disease: a comprehensive review of a growing epidemic. World J Gastroenterol. 2014;20(34):12082.

3 Hashimoto E, Taniai M, Tokushige K. Characteristics and diagnosis of NAFLD/NASH. J Gastroenterol Hepatol. 2013;28:64-70.

4 Byrne CD, Targher G. NAFLD: A multisystem disease. J Hepatol. 2015;62(1):S47-64.

5 Estes C, Razavi H, Loomba R, Younossi Z, Sanyal AJ. Modeling the epidemic of nonalcoholic fatty liver disease demonstrates an exponential increase in burden of disease. Hepatology. 2018;67(1):123-33.

6 Perumpail BJ, Khan MA, Yoo ER, Cholankeril G, Kim D, Ahmed A. Clinical epidemiology and disease burden of nonalcoholic fatty liver disease. World J Gastroenterol. 2017; 23(47):8263-76.

7 Di Minno MN, Russolillo A, Lupoli R, Ambrosino P, Di Minno A, Tarantino G. Omega-3 fatty acids for the treatment of non-alcoholic fatty liver disease. World J Gastroenterol. 2012;18(41):5839.

8 Streba LA, Vere CC, Rogoveanu I, Streba CT Nonalcoholic fatty liver disease, metabolic risk factors, and hepatocellular carcinoma: an open question. World J Gastroenterol. 2015; 21(14):4103.

9 Zelber-Sagi S, Ratziu V, Oren R. Nutrition and physical activity in NAFLD: an overview of the epidemiological evidence. World J Gastroenterol. 2011;17(29):3377-89.

10 Duseja A, Chawla YK. Obesity and NAFLD. Clin Liver Dis. 2014;18(1):59-71.

11 Asrih M, Jornayvaz FR. Inflammation as a potential link between nonalcoholic fatty liver disease and insulin resistance. J Endocrinol. 2013;218(3):R25-36.

12 Mock K, Lateef S, Benedito VA, Tou JC. Highfructose corn syrup-55 consumption alters hepatic lipid metabolism and promotes triglyceride accumulation. J Nutr Biochem. 2017;39:32-9.

13 Jensen T, Abdelmalek MF, Sullivan S, Nadeau KJ, Green M, Roncal C, et al. Fructose and sugar: A major mediator of non-alcoholic fatty liver disease. J Hepatol. 2018;68(5):106375.

14 Mazidi M, Katsiki N, Mikhailidis DP, Banach M. Link between plasma trans-fatty acid and fatty liver is moderated by adiposity. Int J Cardiol. 2018;272:316-22.

15 Rosqvist F, Kullberg J, Ståhlman M, Cedernaes J, Heurling K, Johansson HE, et al. Overeating saturated fat promotes fatty liver and ceramides compared to polyunsaturated fat: a randomized trial. J Clin Endocrinol Metab. 2019;104(12):6207-19.
16 Al-Dayyat HM, Rayyan YM, Tayyem RF. Non-alcoholic fatty liver disease and associated dietary and lifestyle risk factors. Diabetes Metab Syndr. 2018;12(4):569-75.

17 Romero-Gómez M, Zelber-Sagi S, Trenell M. Treatment of NAFLD with diet, physical activity and exercise. J Hepatol. 2017;67(4):82946.

18 Katsagoni CN, Georgoulis M, Papatheodoridis GV, Panagiotakos DB, Kontogianni MD. Effects of lifestyle interventions on clinical characteristics of patients with non-alcoholic fatty liver disease: a meta-analysis. Metabolism. 2017;68:119-32.

19 Goossens N, Jornayvaz FR. Translational aspects of diet and non-alcoholic fatty liver disease. Nutrients. 2017;9(10):1-9.

20 Yoo W, Gjuka D, Stevenson HL, Song X, Shen $\mathrm{H}$, Young Yoo S, et al.: Fatty acids in non-alcoholic steatohepatitis: focus on pentadecanoic acid. PLoS One. 2017;12(12): e0189965.

21 Africa JA, Newton KP, Schwimmer JB. Life style interventions including nutrition, exercise, and supplements for nonalcoholic fatty liver disease in children. Dig Dis Sci. 2016; 61(5):1375-86.

22 Golabi P, Locklear CT, Austin P, Afdhal S, Byrns M, Gerber L, et al. Effectiveness of exercise in hepatic fat mobilization in nonalcoholic fatty liver disease: systematic review. World J Gastroenterol. 2016;22(27):6318.

23 Milić S, Lulić D, Štimac D. Non-alcoholic fatty liver disease and obesity: biochemical, metabolic and clinical presentations. World J Gastroenterol. 2014;20:9330-7.

24 da Silva RP, Kelly KB, Al Rajabi A, Jacobs RL, et al. Novel insights on interactions between folate and lipid metabolism. Biofactors. 2014; 40(3):277-83

25 Song J, da Costa KA, Fischer LM, Kohlmeier M, Kwock L, Wang S, et al. Polymorphism of the PEMT gene and susceptibility to nonalcoholic fatty liver disease (NAFLD). FASEB J. 2005;19(10):1266-71.

26 Sid V, Siow YL: role of folate in nonalcoholic fatty liver disease. Can J Physiol Pharmacol. 2017;95(10):1-8.

27 Lyall MJ, Cartier J, Richards JA, Cobice D, Thomson JP, Meehan RR, et al. Methyl donor deficient diets cause distinct alterations in lipid metabolism but are poorly representative of human NAFLD. Wellcome Open Res. 2017;2:67.

28 Naik A, Košir R, Rozman D. Genomic aspects of NAFLD pathogenesis. Genomics. 2013; 102(2):84-95.

29 Li L, Liu DW, Yan HY, Wang ZY, Zhao SH, Wang B. Obesity is an independent risk factor for non-alcoholic fatty liver disease: evidence from a meta-analysis of 21 cohort studies. Obes Rev. 2016;17(6):510-9.

30 Bjelakovic G, Stojanovic I, Stoimenov TJ, Pavlovic D, Kocic G, Bjelakovic GB, et al. Polyamines, folic acid supplementation and cancerogenesis. Pteridines. 2017;28(3-4):3-4.
31 Nazki FH, Sameer AS, Ganaie BA. Folate: Metabolism, genes, polymorphisms and the associated diseases. Gene. 2014;533(1):11-20.

32 Zeisel SH. Choline, other methyl-donors and epigenetics. Nutrients. 2017;9(5):445.

33 Romano KA, Vivas EI, Amador-Noguez D, Rey FE. Intestinal microbiota composition modulates choline bioavailability from diet and accumulation of the proatherogenic metabolite trimethylamine-N-oxide. MBio. 2015;6(2):e02481.

34 Corbin KD, Zeisel SH: Choline metabolism provides novel insights into nonalcoholic fatty liver disease and its progression. Curr Opin Gastroenterol. 2012 Mar;28(2):159-65.

35 Mato JM, Martínez-Chantar ML, Lu SC. Methionine metabolism and liver disease. Annu Rev Nutr. 2008;28(1):273-93.

36 Finkelstein JD. Methionine metabolism in liver diseases. Am J Clin Nutr. 2003;77(5): 1094-5.

37 Pacana T, Cazanave S, Verdianelli A, Patel V, Min HK, Mirshahi F, et al. Dysregulated hepatic methionine metabolism drives homocysteine elevation in diet-induced nonalcoholic fatty liver disease. PLoS One. 2015; 10(8):e0136822.

38 García-Tevijano ER, Berasain C, Rodríguez JA, Corrales FJ, Arias R, Martín-Duce A, et al. Hyperhomocysteinemia in liver cirrhosis: mechanisms and role in vascular and hepatic fibrosis. Hypertension. 2001;38:1217-21.

39 Niculescu MD, Zeisel SH. Diet, methyl donors and DNA methylation: interactions between dietary folate, methionine and choline. J Nutr. 2002;132(8):2333S-5S.

40 Itagaki H, Shimizu K, Morikawa S, Ogawa K, Ezaki T. Morphological and functional characterization of non-alcoholic fatty liver disease induced by a methionine-choline-deficient diet in C57BL/6 mice. Int J Clin Exp Pathol. 2013;6:2683-96.

41 Machado MV, Cortez-Pinto H. Non-alcoholic fatty liver disease: what the clinician needs to know. World J Gastroenterol. 2014;20(36): 12956-80.

42 Rinella ME, Elias MS, Smolak RR, Fu T, Borensztajn J, Green RM. Mechanisms of hepatic steatosis in mice fed a lipogenic methionine choline-deficient diet. J Lipid Res. 2008;49(5): 1068-76.

43 Caballero F, Fernández A, Matías N, Martínez L, Fucho R, Elena M, et al. Specific contribution of methionine and choline in nutritional nonalcoholic steatohepatitis: impact on mitochondrial S-adenosyl-L-methionine and glutathione. J Biol Chem. 2010;285(24):18528-36.

44 Yao ZM, Vance DE. The active synthesis of phosphatidylcholine is required for very low density lipoprotein secretion from rat hepatocytes. J Biol Chem. 1988;263:2998-3004.

45 Vance JE, Vance DE. The role of phosphatidylcholine biosynthesis in the secretion of lipoproteins from hepatocytes. Can J Biochem Cell Biol. 1985;63(8):870-81. 
46 Rizki G, Arnaboldi L, Gabrielli B, Yan J, Lee GS, Ng RK, et al. Mice fed a lipogenic methionine-choline-deficient diet develop hypermetabolism coincident with hepatic suppression of SCD-1. J Lipid Res. 2006;47(10):2280-90.

47 Aissa AF, Tryndyak V, de Conti A, Melnyk S, Gomes TD, Bianchi ML, et al. Effect of methionine-deficient and methionine-supplemented diets on the hepatic one-carbon and lipid metabolism in mice. Mol Nutr Food Res. 2014;58(7):1502-12.

48 Martínez-Uña M, Varela-Rey M, Cano A, Fernández-Ares L, Beraza N, Aurrekoetxea I, et al. Excess S-adenosylmethionine reroutes phosphatidylethanolamine towards phosphatidylcholine and triglyceride synthesis. Hepatology. 2013;58(4):1296-305.

49 Yamada H, Akahoshi N, Kamata S, Hagiya Y, Hishiki T, Nagahata Y, et al. Methionine excess in diet induces acute lethal hepatitis in mice lacking cystathionine $\gamma$-lyase, an animal model of cystathioninuria. Free Radic Biol Med. 2012;52(9):1716-26.

50 Stephenson K, Kennedy L, Hargrove L, Demieville J, Thomson J, Alpini G, et al. Updates on dietary models of nonalcoholic fatty liver disease: current studies and insights. Gene Expr. 2018;18(1):5-17.

51 Huang RF, Hsu YC, Lin HL, Yang FL. Folate depletion and elevated plasma homocysteine promote oxidative stress in rat livers. J Nutr. 2001;131(1):33-8.

52 Christensen KE, Wu Q, Wang X, Deng L, Caudill MA, Rozen R. steatosis in mice is associated with gender, folate intake, and expression of genes of one-carbon metabolism. J Nutr. 2010;140(10):1736-41.

53 Champier J, Claustrat F, Nazaret N, Montange MF, Claustrat B. Folate depletion changes gene expression of fatty acid metabolism, DNA synthesis, and circadian cycle in male mice. Nutr Res. 2012;32(2):124-32.

54 Moessinger C, Klizaite K, Steinhagen A, Philippou-Massier J, Shevchenko A, Hoch M, et al. Two different pathways of phosphatidylcholine synthesis, the Kennedy Pathway and the Lands Cycle, differentially regulate cellular triacylglycerol storage. BMC Cell Biol. 2014;15(1):43.

55 Bakir MB, Salama MA, Refaat R, Ali MA, Khalifa EA, Kamel MA. Evaluating the therapeutic potential of one-carbon donors in nonalcoholic fatty liver disease. Eur J Pharmacol. 2019;847:72-82.

56 Liu Y, Shen J, Yang X, Sun Q, Yang X. Folic acid reduced triglycerides deposition in primary chicken hepatocytes. J Agric Food Chem. 2018;66(50):13162-72.

57 McNeil CJ, Hay SM, Rucklidge GJ, Reid M, Duncan G, Maloney CA, et al. Disruption of lipid metabolism in the liver of the pregnant rat fed folate-deficient and methyl donor-deficient diets. Br J Nutr. 2008;99(2):262-71.

58 Christensen KE, Mikael LG, Leung KY, Lévesque N, Deng L, Wu Q, et al. High folic acid consumption leads to pseudo-MTHFR deficiency, altered lipid metabolism, and liver injury in mice. Am J Clin Nutr. 2015;101(3): 646-58.

59 Polyzos SA, Kountouras J, Patsiaoura K, Katsiki E, Zafeiriadou E, Zavos C, et al. Serum vitamin B12 and folate levels in patients with non-alcoholic fatty liver disease. Int J Food Sci Nutr. 2012;63(6):659-66.

60 Brochado MJ, Domenici FA. Methylenetetrahydrofolate reductase gene polymorphism and serum homocysteine levels in nonalcoholic fatty liver disease. Ann Nutr Metab. 2013;63(3):193-9.

61 Xia MF, Bian H, Zhu XP, Yan HM, Chang XX, Zhang LS, et al. Serum folic acid levels are associated with the presence and severity of liver steatosis in Chinese adults. Clin Nutr. 2018; 37(5):1752-8

62 Mahamid M, Mahroum N, Bragazzi N, Shalaata $\mathrm{K}$, Yavne $\mathrm{Y}$, Adawi $\mathrm{M}$, et al. Folate and B12 levels correlate with histological severity in NASH patients. Nutrients. 2018;10(4):440.

63 Mahabir S, Ettinger S, Johnson L, Baer DJ, Clevidence BA, Hartman TJ, et al. Measures of adiposity and body fat distribution in relation to serum folate levels in postmenopausal women in a feeding study. Eur J Clin Nutr. 2008;62(5):644-50.

64 Sid V, Siow YL, Shang Y, Woo CW, O K. High-fat diet consumption reduces hepatic folate transporter expression via nuclear respiratory factor-1. J Mol Med (Berl). 2018 Nov;96(11):1203-13.

65 Veteläinen R, van Vliet A, van Gulik TM. Essential pathogenic and metabolic differences in steatosis induced by choline or methionecholine deficient diets in a rat model. J Gastroenterol Hepatol. 2007;22(9):1526-33.

66 Walkey CJ, Yu L, Agellon LB, Vance DE. Biochemical and evolutionary significance of phospholipid methylation. J Biol Chem. 1998; 273(42):27043-6.

67 Waite KA, Cabilio NR, Vance DE. Choline deficiency-induced liver damage is reversible in Pemt-/- Mice. J Nutr. 2002;132(1):68-71.

68 Zeisel SH, Da Costa KA, Franklin PD, Alexander EA, Lamont JT, Sheard NF, et al. Choline, an essential nutrient for humans. FASEB J. 1991;5(7):2093-8.

69 Guerrerio AL, Colvin RM, Schwartz AK, Molleston JP, Murray KF, Diehl A, et al. Choline intake in a large cohort of patients with nonalcoholic fatty liver. Am J Clin Nutr. 2012; 95:892-900.

70 Yu D, Shu XO, Xiang YB, Li H, Yang G, Gao YT, et al. Higher dietary choline intake is associated with lower risk of nonalcoholic fatty liver in normal-weight Chinese women. J Nutr. 2014;144(12):2034-40

71 Fischer LM, daCosta KA, Kwock L, Stewart PW, Lu TS, Stabler SP, et al. Sex and menopausal status influence human dietary requirements for the nutrient choline. Am J Clin Nutr. 2007;85(5):1275-85.

72 Fischer LM, Da Costa KA, Kwock L, Galanko J, Zeisel SH. Dietary choline requirements of women: effects of estrogen and genetic variation. Am J Clin Nutr. 2010;92(5):1113-9.
73 Ballestri S, Nascimbeni F, Baldelli E, Marrazzo A, Romagnoli D, Lonardo A. NAFLD as a sexual dimorphic disease: role of gender and reproductive status in the development and progression of nonalcoholic fatty liver disease and inherent cardiovascular risk. Adv Ther. 2017;34(6):1291-326.

74 Buchman AL, Dubin MD, Moukarzel AA, Jenden DJ, Roch M, Rice KM, et al. Choline deficiency: a cause of hepatic steatosis during parenteral nutrition that can be reversed with intravenous choline supplementation. Hepatology. 1995;22:1399-403.

75 Kathirvel E, Morgan K, Nandgiri G, Sandoval BC, Caudill MA, Bottiglieri T, et al. Betaine improves nonalcoholic fatty liver and associated hepatic insulin resistance: a potential mechanism for hepatoprotection by betaine. Am J Physiol Gastrointest Liver Physiol. 2010 Nov;299(5):G1068-77.

76 Song Z, Deaciuc I, Zhou Z, Song M, Chen T, Hill D, et al. Involvement of AMP-activated protein kinase in beneficial effects of betaine on high-sucrose diet-induced hepatic steatosis. Am J Physiol Liver Physiol. 2007;293(4): G894-902.

77 Kharbanda KK, Todero SL, Ward BW, Cannella JJ, Tuma DJ. Betaine administration corrects ethanol-induced defective VLDL secretion. Mol Cell Biochem. 2009;327(1-2):75-8.

78 Ji C, Kaplowitz N. Betaine decreases hyperhomocysteinemia, endoplasmic reticulum stress, and liver injury in alcohol-fed mice. Gastroenterology. 2003;124(5):1488-99.

79 Yang W, Huang L, Gao J, Wen S, Tai Y, Chen $\mathrm{M}$, et al. Betaine attenuates chronic alcohol-induced fatty liver by broadly regulating hepatic lipid metabolism. Mol Med Rep. 2017; 16(4):5225-34.

80 Wu S, Zhang J, Li F, Du W, Zhou X, Wan M, et al. One-carbon metabolism links nutrition intake to embryonic development via epigenetic mechanisms. Stem Cells Int. 2019;2019:1-8.

81 Cordero P, Gomez-Uriz AM, Campion J, Milagro FI, Martinez JA. Dietary supplementation with methyl donors reduces fatty liver and modifies the fatty acid synthase DNA methylation profile in rats fed an obesogenic diet. Genes Nutr. 2013;8(1):105-13.

82 Cordero P, Campion J, Milagro FI, Martinez JA. Transcriptomic and epigenetic changes in early liver steatosis associated to obesity: effect of dietary methyl donor supplementation. Mol Genet Metab. 2013;110(3):38895.

83 Dahlhoff C, Worsch S, Sailer M, Hummel BA, Fiamoncini J, Uebel K, et al. Methyl-donor supplementation in obese mice prevents the progression of NAFLD, activates AMPK and decreases acyl-carnitine levels. Mol Metab. 2014;3(5):565-80.

84 Al Rajabi A, Castro GS, da Silva RP, Nelson RC, Thiesen A, Vannucchi H, et al. Choline supplementation protects against liver damage by normalizing cholesterol metabolism in Pemt/Ldlr knockout mice fed a high-fat diet. J Nutr. 2014;144(3):252-7. 
85 Schnabl B, Brenner DA. Interactions between the intestinal microbiome and liver diseases. Gastroenterology. 2014;146(6):1513-24.

86 Spencer MD, Hamp TJ, Reid RW, Fischer LM, Zeisel SH, Fodor AA. Association between composition of the human gastrointestinal microbiome and development of fatty liver with choline deficiency. Gastroenterology. 2011;140(3):976-86.

87 Zhu L, Baker SS, Gill C, Liu W, Alkhouri R, Baker RD, et al. Characterization of gut microbiomes in nonalcoholic steatohepatitis (NASH) patients: A connection between endogenous alcohol and NASH. Hepatology. 2013;57(2):601-9.

88 Yuan J, Chen C, Cui J, Lu J, Yan C, Wei X, et al. Fatty liver disease caused by high-alcohol-producing Klebsiella pneumoniae. Cell Metab. 2019;30(4):675-688.e7.

89 Michail S, Lin M, Frey MR, Fanter R, Paliy O, Hilbush B, et al. Altered gut microbial energy and metabolism in children with non-alcoholic fatty liver disease. FEMS Microbiol Ecol. 2015;91(2):1-9.

90 Zhu L, Baker RD, Zhu R, Baker SS. Gut microbiota produce alcohol and contribute to NAFLD. Gut. 2016;65(7):1232.

91 Rossi M, Amaretti A, Raimondi S. Folate production by probiotic bacteria. Nutrients. 2011;3(1):118-34.

92 Dumas ME, Barton RH, Toye A, Cloarec O, Blancher C, Rothwell A, et al. Metabolic profiling reveals a contribution of gut microbiota to fatty liver phenotype in insulin-resistant mice. Proc Natl Acad Sci USA. 2006;103(33): 12511-6.

93 Chen Y, Liu Y, Zhou R, Chen X, Wang C, Tan $\mathrm{X}$, et al. Associations of gut-flora-dependent metabolite trimethylamine- $\mathrm{N}$-oxide, betaine and choline with non-alcoholic fatty liver disease in adults. Sci Rep. 2016;6(1):19076.

94 Al-Rubaye H, Perfetti G, Kaski JC. The role of microbiota in cardiovascular risk: focus on trimethylamine oxide. Curr Probl Cardiol. 2019;44(6):182-96.

95 Koeth RA, Wang Z, Levison BS, Buffa JA, Org E, Sheehy BT, et al. Intestinal microbiota metabolism of L-carnitine, a nutrient in red meat, promotes atherosclerosis. Nat Med. 2013;19(5):576-85.

96 Imajo K, Fujita K, Yoneda M, Shinohara Y, Suzuki K, Mawatari H, et al. Plasma free choline is a novel non-invasive biomarker for early-stage non-alcoholic steatohepatitis: A multi-center validation study. Hepatol Res. 2012;42(8):757-66.

97 Adams LA, White SW, Marsh JA, Lye SJ, Connor KL, Maganga R, et al. Association between liver-specific gene polymorphisms and their expression levels with nonalcoholic fatty liver disease. Hepatology. 2013;57(2):590600.

98 Marzuillo P, Del Giudice EM, Santoro N. Pediatric non-alcoholic fatty liver disease: new insights and future directions. World J Hepatol. 2014;6(4):217.
99 Garner CJ, Conn CA, Cohen D, Luo L, Castillo JJ, Shah VO, et al. NAFLD susceptibility genes and their association with type 2 diabetes and obesity in a New Mexico population. J Diabetes Obes. 2015;2(2):1-12.

100 Dong H, Wang J, Li C, Hirose A, Nozaki Y Takahashi M, et al. The phosphatidylethanolamine N-methyltransferase gene V175M single nucleotide polymorphism confers the susceptibility to NASH in Japanese population. J Hepatol. 2007;46(5):915-20.

101 Kohlmeier M, da Costa KA, Fischer LM, Zeisel SH. Genetic variation of folate-mediated one-carbon transfer pathway predicts susceptibility to choline deficiency in humans. Proc Natl Acad Sci USA. 2005;102(44): 16025-30.

102 Brochado MJ, Domenici FA, Martinelli AL, Zucoloto S, de Carvalho da Cunha SF, Vannucchi H. Methylenetetrahydrofolate reductase gene polymorphism and serum homocysteine levels in nonalcoholic fatty liver disease. Ann Nutr Metab. 2013;63(3): 193-9.

103 Sun MY, Zhang L, Shi SL, Lin JN. Associations between methylenetetrahydrofolate reductase (MTHFR) polymorphisms and non-alcoholic fatty liver disease (NAFLD) risk: a meta-analysis. PLoS One. 2016;11(4): e0154337.

104 Corbin KD, Abdelmalek MF, Spencer MD, da Costa KA, Galanko JA, Sha W, et al. Genetic signatures in choline and 1-carbon metabolism are associated with the severity of hepatic steatosis. FASEB J. 2013;27(4):167489.

105 Saffery R, Novakovic B. Epigenetics as the mediator of fetal programming of adult onset disease: what is the evidence? Acta Obstet Gynecol Scand. 2014;93(11):1090-8

106 Li M, Reynolds CM, Segovia SA, Gray C, Vickers $\mathrm{MH}$. Developmental programming of nonalcoholic fatty liver disease: the effect of early life nutrition on susceptibility and disease severity in later life. Biomed Res Int. 2015;2015:437107.

107 Campisano SE, Echarte SM, Podaza E, Chisari AN. Protein malnutrition during fetal programming induces fatty liver in adult male offspring rats. J Physiol Biochem. 2017;73(2): 275-85.

108 Ganz AB, Klatt KC, Caudill MA. Common genetic variants alter metabolism and influence dietary choline requirements. Nutrients. 2017;9(8):837.

109 Oben JA, Mouralidarane A, Samuelsson AM, Matthews PJ, Morgan ML, Mckee C, et al. Maternal obesity during pregnancy and lactation programs the development of offspring non-alcoholic fatty liver disease in mice. Hepatol. 2010;52(6):913-20.

110 Stewart MS, Heerwagen MJ, Friedman JE. Developmental programming of pediatric nonalcoholic fatty liver disease: redefining the "first hit". Clin Obstet Gynecol. 2013 Sep; 56(3):577-90.
111 McNeil CJ, Hay SM, Rucklidge GJ, Reid MD Duncan GJ, Rees WD. Maternal diets deficient in folic acid and related methyl donors modify mechanisms associated with lipid metabolism in the fetal liver of the rat. $\mathrm{Br}$ ) Nutr. 2009;102(10):1445-52.

112 Blaise SA, Alberto JM, Audonnet-Blaise S, Guéant JL, Daval JL. Influence of preconditioning-like hypoxia on the liver of developing methyl-deficient rats. Am J Physiol Metab. 2007;293(6):E1492-502.

113 Pooya S, Blaise S, Moreno Garcia M, Giudicelli J, Alberto JM, Guéant-Rodriguez RM, et al. Methyl donor deficiency impairs fatty acid oxidation through PGC-1a hypomethylation and decreased ER- $\alpha$, ERR- $\alpha$, and HNF- $4 \alpha$ in the rat liver. J Hepatol. 2012;57(2):344-51.

114 Wang N, Chen Y, Ning Z, Li Q, Han B, Zhu C, et al. Exposure to famine in early life and nonalcoholic fatty liver disease in adulthood. J Clin Endocrinol Metab. 2016;101(5):2218-25.

115 Sandboge S, Perälä MM, Salonen MK, Blomstedt PA, Osmond C, Kajantie E, et al. Early growth and non-alcoholic fatty liver disease in adulthood - the NAFLD liver fat score and equation applied on the Helsinki Birth Cohort Study. Ann Med. 2013;45(5-6):430-7.

116 Modi N, Murgasova D, Ruager-Martin R, Thomas EL, Hyde MJ, Gale C, et al. The influence of maternal body mass index on infant adiposity and hepatic lipid content. Pediatr Res. 2011;70(3):287-91.

117 Newton KP, Feldman HS, Chambers CD Wilson L, Behling C, Clark JM, et al. Low and high birth weights are risk factors for nonalcoholic fatty liver disease in children. J Pediatr. 2017;187:141-146.e1.

118 Brøns C, Justesen L. Fetal programming of fatty liver disease: the human gut-liver-axis in health and disease. Cham: Springer; 2019. p. $65-80$.

119 Nowacka-Woszuk J, Grzemski A, Sliwinska M, Chmurzynska A. Hepatic DNA methylation and expression profiles under prenatal restricted diet in three generations of female rat fetuses. PLoS One. 2019;14(4):e0215471.

120 Kawaguchi T, Shima T, Mizuno M, Mitsumoto Y, Umemura A, Kanbara Y, et al. Risk estimation model for nonalcoholic fatty liver disease in the Japanese using multiple genetic markers. PLoS One. 2018;13(1):e0185490.

121 Chung GE, Lee Y, Yim JY, Choe EK, Kwak MS, Yang JI, et al. Genetic Polymorphisms of PNPLA3 and SAMM50 Are Associated with Nonalcoholic Fatty Liver Disease in a Korean Population. Gut Liver. 2018 May;12(3):31623.

122 Catalano D, Trovato GM, Ragusa A, Martines GF, Tonzuso A, Pirri C, et al. Non-alcoholic fatty liver disease (NAFLD) and MTHFR 1298A [\{GT\}] C gene polymorphism. Eur Rev Med Pharmacol Sci. 2014;18(2):151-9.

123 Sazci A, Ergul E, Aygun C, Akpinar G, Senturk O, Hulagu S. Methylenetetrahydrofolate reductase gene polymorphisms in patients with nonalcoholic steatohepatitis (NASH). Cell Biochem Funct. 2008 Apr;26(3):291-6. 